\title{
Involvement of Dietary Fatty Acids in Multiple Biological and Psychological Functions, in Morbidly Obese Subjects
}

\author{
Anne Chalut-Carpentier • Zoltan Pataky • Alain Golay • \\ Elisabetta Bobbioni-Harsch
}

Published online: 6 November 2014

(C) Springer Science+Business Media New York 2014

\begin{abstract}
Background Fatty acid (FA) profile is often altered, in morbidly obese subjects, both before and after bariatric surgery. We measured FA plasma levels before and 6 months after Roux-en-Y gastric bypass (RYGB), in order to evaluate their relationship with different biological and psychological parameters and the impact of RYGB on the FA plasma levels. Methods Thirty eight morbidly obese patients were investigated before RYGB, and 28 of them were reexamined 6 months postoperatively. Anxiety, depression, and quality of life were evaluated by validated questionnaires. Plasma FA (saturated, monounsaturated, polyunsaturated $\omega-6$ and $\omega-3)$, vitamins $\mathrm{A}$ and $\mathrm{E}$, fasting insulinemia, and highsensitive C-reactive protein (hs-CRP) were measured.

Results Before surgery, $\omega-3$ polyunsaturated FA and vit A showed significant negative relationship with fasting insulinemia ( $\gamma$-linolenic $p=0.03$, eicosapentaenoic, vit $\mathrm{A} p=$ 0.01 ) and hs-CRP (eicosapentaenoic $p=0.03$, vit A $p=0.02$ ) and a positive link with HDL cholesterol $(\gamma$-linolenic $p=0.03$, vit $\mathrm{A} p=0.02)$. Depression score was significantly and negatively linked with palmitoleic $(p=0.03), \gamma$-linolenic $(p=$
\end{abstract}

\author{
A. Chalut-Carpentier $\cdot$ Z. Pataky $(\triangle) \cdot$ A. Golay $\cdot$ \\ E. Bobbioni-Harsch \\ Service of Therapeutic Education for Chronic Diseases, WHO \\ Collaborating Centre, University Hospitals of Geneva, Gabrielle \\ Perret-Gentil 4, 1211 Geneva 14, Switzerland \\ e-mail: zoltan.pataky@hcuge.ch \\ A. Chalut-Carpentier \\ e-mail: anne.carpetier@hcuge.ch \\ A. Golay \\ e-mail: alain.golay@hcuge.ch \\ E. Bobbioni-Harsch \\ e-mail: elisabetta.harsch@gmail.com
}

A. Chalut-Carpentier · Z. Pataky $\cdot$ A. Golay $\cdot$ E. Bobbioni-Harsch University of Geneva, Geneva, Switzerland
$0.006)$, dihomo- $\gamma$-linolenic $(p=0.02)$, and $\alpha$-linolenic $(p=$ 0.03 ) acids. After surgery, FA and both vit $\mathrm{A}$ and $\mathrm{E}$ were significantly reduced. Vit A levels were below $2.4 \mu \mathrm{mol} / 1$ in $63 \%$ of the patients, preoperatively, and in $79 \%$ after surgery. Preoperative levels of linoleic acid were significantly related with the postoperative weight reduction $(p=0.0006)$. Conclusions FA are involved in several biological and psychological functions. The RYGB-induced reduction of FA could have deleterious consequences on vitamin absorption, metabolism, and depression. Thus, the surveillance of FA levels is of primary importance both before and after RYGB.

Keywords Roux-en-Y gastric bypass $\cdot$ Fatty acids $\cdot$ Vitamin A · Vitamin E

\section{Introduction}

Morbid obesity, the extreme form of obesity, is rapidly increasing, in both adult [1] and young people [2]. It is well known that this illness is associated with several physical [3] and psychological comorbidities as well as with reduced quality of life [4].

Bariatric surgery, and in particular Roux-en-Y gastric bypass (RYGB), is the most effective treatment of this illness: in fact, in the majority of the patients, it yields a remarkable weight reduction which, in turn, leads to an improvement of both comorbidities [5] and quality of life [6]. However, surgically induced food restriction and intestinal malabsorption can alter the micronutritional status [7, 8], namely concerning polyunsaturated fatty acid profiles. These compounds play an important role in multiple functions, such as immunity, inflammation, or metabolism, and seem to exert a protective action against cardiovascular diseases [9], although this last effect has been questioned [10]. 
It should be noticed that obesity is often associated with poor alimentary habits as well as imbalanced gut microbiota: these factors per se are able to deeply modify the micronutritional profile [11-13], independent of any surgical intervention. Because of the remarkable alterations of the micronutritional profile, some authors suggest that malnutrition coexists with obesity [14].

Finally, a number of studies indicate the links between the micronutritional profile and some psychological alterations: for instance, some vitamins [15] and fatty acids [16, 17] seem to influence depression.

Thus, obese patients need a close surveillance of both biological and micronutritional parameters, in particular after a bariatric surgery intervention.

For these reasons, in our study, we have investigated some micronutritional parameters, in a group of morbidly obese patients before and 6 months after RYGB. We focused on circulating fatty acid (FA) profile and liposoluble vitamin A and $\mathrm{E}$ levels, in order to evaluate, in preoperative conditions, their links with different biological and psychological parameters and, in postoperative phase, the surgically induced modifications of their circulating levels.

\section{Material and Methods}

In this study, 38 patients $(7 \mathrm{~m} / 31 \mathrm{f}$. age $43 \pm 9$ years [range $43-$ 52], BMI 46.3 \pm 6.8 ) were investigated before a RYGB. Among them, 11 subjects did not complete the study at 6 months. There were no statistically significant differences between the whole group and the subgroup of 27 subjects. We reexamined 27 subjects $(4 \mathrm{~m} / 23$ f. 6 months after the operation. Body weight, percent body fat, and fat-free mass were evaluated by the Tanita ${ }^{\circledR}$ bioimpedance scale (Tanita International Division, Yiewsley, UK).

\section{Evaluation of Psychological and Quality of Life Parameters}

Patients were evaluated in terms of anxiety and depression (hospital anxiety and depression scale (HAD)) [18] and quality of life (Impact of Weight on Quality of Life-Lite (IWQOLLite(C)) [19]. This latter is a 31-item questionnaire evaluating physical activity, self esteem, and sexual, professional, and social life. All parameters were measured before and 6 months after RYGB.

\section{Laboratory Parameters}

Saturated (myristic, pentadecanoic, palmitic, stearic), monounsaturated (palmitoleic, cis-vaccenic, oleic, trans-vaccenic, trans-elaidic), and polyunsaturated $\omega-6$ (linoleic, $\gamma$-linolenic, dihomo- $\gamma$-linolenic, arachidonic) and $\omega$-3 FA ( $\alpha$-linolenic, eicosapentaenoic, docosa-pentaenoic, docosahexaenoic) were measured in blood samples, after extraction of lipoproteins by adsorption chromatography, as described in details by Chajes et al. [20]. Circulating vitamins A and E were measured by high-pressure liquid chromatography [21], whereas fasting insulinemia and high-sensitive C-reactive protein (hs-CRP) were measured by automatic analyzer (Architect eSystem). Vitamins $\mathrm{B}_{6}, \mathrm{~B}_{12}$, and $\mathrm{D}$ were not measured since they are systematically administered, after the intervention.

\section{Statistical Analysis}

Relationships between different parameters were evaluated by simple and multiple regression analysis; analysis of variance for repeated measurements was used to investigate the modifications occurring after the intervention. Statistical analyses were performed by a computerized program (StatView 5). Results are expressed as mean $\pm \mathrm{SD}$.

\section{Results}

Table 1 illustrates the baseline values of anthropometric, biological, and psychological parameters and their modifications 6 months after RYGB. Values reported in brackets refer to the overall group including subjects who did not complete the study at 6 months. No significant differences were observed between the overall and the completers group. BMI was dramatically reduced, as well as fasting insulinemia and plasma hs-CRP, total and LDL cholesterol ( $p<0.0001$ for all), whereas HDL cholesterol was not significantly changed.

No significant modifications were observed in anxiety or depression parameters, whereas quality of life showed significant improvement in all the domains investigated, with the exception of sexual life.

Within the family of saturated FA, palmitic and stearic acids were significantly reduced after surgery $(p<0.003$ and $p<0.0001$, respectively). Among monounsaturated FA, palmitoleic $(p<0.003)$, cis-vaccenic $(p<0.01)$, and transvaccenic $(p<0.002)$ were mostly influenced, after the surgical intervention. All the polyunsaturated FA, both $\omega-6$ and $\omega-3$, were significantly reduced after RYGB, with the exception of arachidonic and docosahexaenoic acids.

In preoperative conditions, several polyunsaturated $\omega-3$ FA showed significant relationships with various metabolic parameters associated with obesity. In fact, $\gamma$-linolenic acid was negatively related to insulin and positively to HDL cholesterol ( $p=0.03$ for both); eicosapentaenoic acid was inversely related to both fasting insulinemia and hs-CRP ( $p=0.04$ and $p=0.03$, respectively), and docosahexaenoic acid was inversely related to hs-CRP $(p=0.03)$ and positively to HDL cholesterol $(p=0.04)$. 
Table 1 Anthropometric, biological, and psychological parameters, measured at baseline and 6 months after RYGB

\begin{tabular}{llll}
\hline & $\begin{array}{l}\text { Baseline } \\
n=27\end{array}$ & $\begin{array}{l}6 \text { months after RYGB } \\
n=27\end{array}$ & $p$ value \\
\hline BMI $\left(\mathrm{kg} / \mathrm{m}^{2}\right)$ & $45.5 \pm 7.5(46.3 \pm 6.8)$ & $33.6 \pm 5.4$ & $<0.0001$ \\
Fasting insulin (mU/l) & $21.0 \pm 14.8(21.4 \pm 13.8)$ & $7.6 \pm 4.3$ & $<0.0001$ \\
hs-CRP (mg/l) & $12.5 \pm 9.7(12.9 \pm 9.7)$ & $4.6 \pm 4.2$ & $<0.0001$ \\
Total cholesterol (mmol/l) & $5.0 \pm 0.8(5.8 \pm 0.9)$ & $4.24 \pm 0.8$ & $<0.0001$ \\
LDL cholesterol (mmol/l) & $3.2 \pm 0.7(3.5 \pm 0.8)$ & $2.6 \pm 0.8$ & $<0.0001$ \\
HDL cholesterol (mmol/l) & $1.2 \pm 0.3(1.2 \pm 0.3)$ & $1.2 \pm 0.2$ & $\mathrm{NS}$ \\
HAD anxiety (score) & $11.4 \pm 2.0(10.9 \pm 2.4)$ & $10.6 \pm 1.9$ & $\mathrm{NS}$ \\
HAD depression (score) & $11.8 \pm 2.8(11.9 \pm 2.4)$ & $11.6 \pm 2.7$ & $\mathrm{NS}$ \\
IWQOL public distress (score) & $14.7 \pm 5.1(15.2 \pm 5.1)$ & $8.1 \pm 4.4$ & $<0.0001$ \\
IWQOL work (score) & $9.4 \pm 4.9(10.6 \pm 5.1)$ & $6.8 \pm 3.2$ & 0.001 \\
IWQOL self esteem (score) & $27.2 \pm 6.4(27.5 \pm 6.5)$ & $17.8 \pm 5.9$ & $<0.0001$ \\
IWQOL sexual life (score) & $12.0 \pm 6.0(12.1 \pm 5.5)$ & $9.6 \pm 5.7$ & $\mathrm{NS}(0.05)$ \\
IWQOL mobility (score) & $40.0 \pm 11(41.3 \pm 10.4)$ & $22.3 \pm 10.1$ & $<0.0001$ \\
\hline
\end{tabular}

Before surgery, all the members of the saturated FA group showed a weak association with vit $\mathrm{A}$, and this link became stronger with pentadecanoic and stearic acids, after surgery. Conversely, dihomo- $\gamma$-linolenic acid, which was not significantly related to vit $\mathrm{A}$, in preoperative conditions, became so, after surgery. Polyunsaturated $\omega$-3 eicosapentaenoic and docosa-pentaenoic acids showed the strongest association with vit A circulating levels. Postoperatively, this association persists, but with a weaker degree of significance.
In preoperative conditions, several FA showed a strong relationship with vit $\mathrm{E}$ circulating levels: palmitic and stearic in the saturated group, oleic and transvaccenic in the monounsaturated group. All the polyunsaturated FA were associated with vit $\mathrm{E}$ and, namely, linoleic and arachidonic acids. Among polyunsaturated $\omega-3, \alpha$-linolenic acid was the most significantly linked to vit $\mathrm{E}$.

Postoperatively, the majority of these associations persisted, but with a weaker degree of significance.
Fig. 1 Relationship between HAD depression score and palmitoleic (a), $\gamma$-linolenic (b), $\alpha$ linolenic (c), and dihomo- $\gamma$ linolenic (d) acids
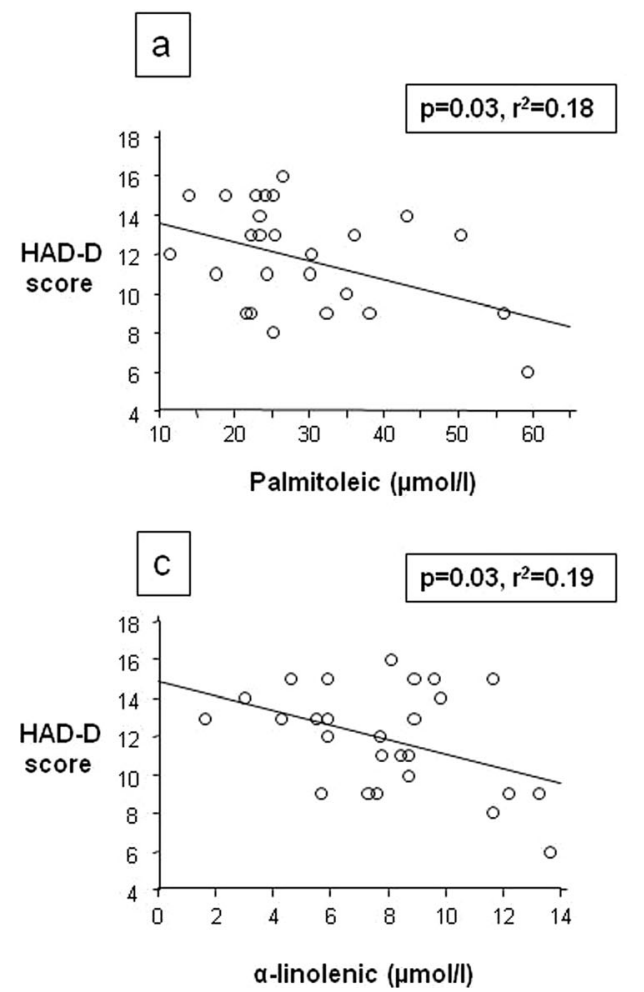
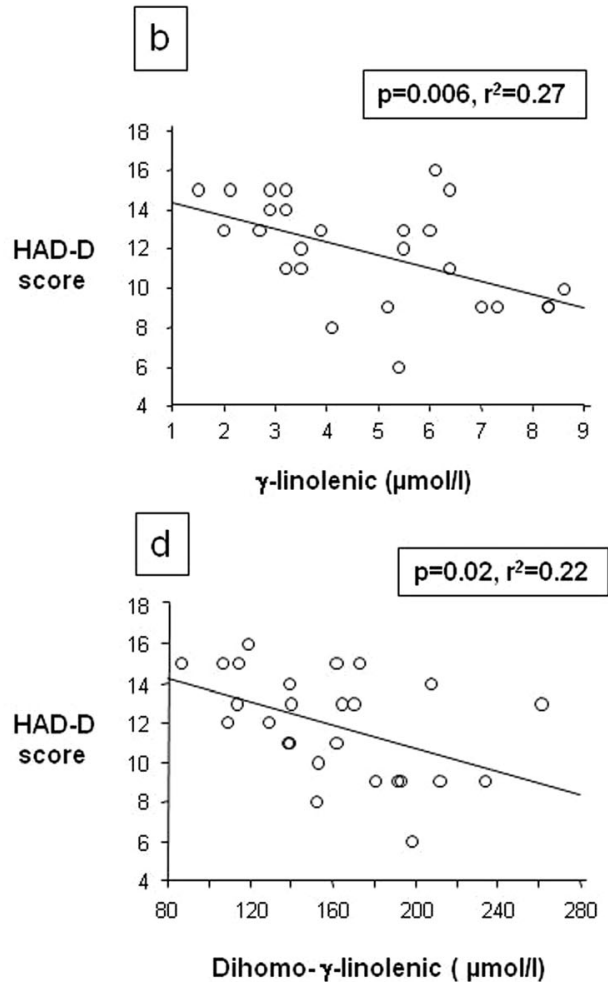


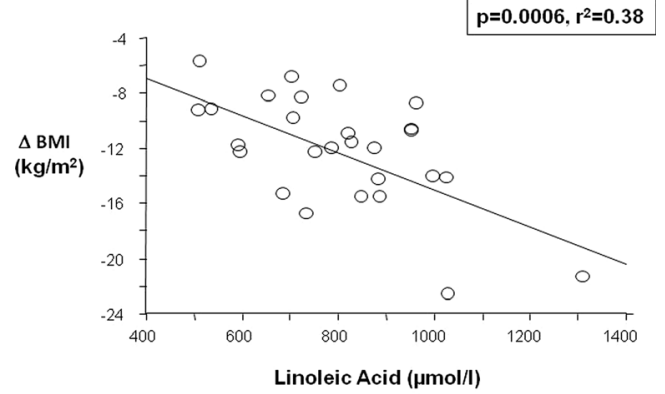

Fig. 2 Relationship between BMI modifications and plasma linoleic acid levels

In preoperative phase, the following FA showed a significant, negative link with the depression score: monounsaturated palmitoleic ( $p=0.03$, Fig. 1a), trans-vaccenic $(p=0.04)$, and trans-elaidic $(p=0.005)$; polyunsaturated $\omega-6 \gamma$-linolenic ( $p=0.006$, Fig. 1b), polyunsaturated $\omega-3 \alpha$-linolenic $(p=0.03$, Fig. 1c), and dihomo- $\gamma$-linolenic ( $p=0.02$, Fig. 1d).

Figure 2 shows that preoperative levels of linoleic acid are predictive of the BMI modifications, measured 6 months after RYGB $(p=0.0006)$. This relationship remained significant after adjustment for preoperative BMI, in a multiple regression analysis.

In preoperative conditions, vit $\mathrm{A}$ is negatively related to circulating fasting insulinemia ( $p=0.01$, Fig. $3 a)$ and hs-CRP $(p=0.02$, Fig. $3 \mathrm{~b})$ and positively with HDL cholesterol $(p=$ 0.02 , Fig. 3c).

In simple regression analysis, we observed a significant relationship between the modifications of circulating vit $\mathrm{A}$, and those of fat mass, both calculated as the difference between baseline and 6 months delta values $\left(p=0.03, r^{2}=0.18\right)$.

\section{Discussion}

In our study, we focused on two aspects of micronutrition: the levels and composition of circulating FA and vitamins A and $\mathrm{E}$, as well as their modifications after gastric bypass.

In preoperative conditions, the most relevant result concerns the significant, negative association between several FA and the degree of depression (Fig. 1). Since several years, a great interest has been attributed to the potential, beneficial role played by $\omega-3$ FA on depression and more generally mental health. This potential role has been investigated in both epidemiological and experimental studies which, unfortunately, have yielded contrasting results. In fact, while the fish consumption has been reported to be inversely associated with frequency and incidence of depression [22, 23], this protective effect has not been observed, in other reports [24]. Similarly, supplementation with $\omega-3$ FA seems to improve depressive symptoms in some patients [17], but not in others [25]. Recently, Grosso et al. have remarkably analyzed these inconsistencies and proposed possible explanations [17]. There are numerous reasons for these contrasting results, such as differences in sex, age, or criteria selected for the evaluation of depression. The heterogeneity in both lifestyle and nutritional conditions, across the different study populations, is
Fig. 3 Relationship between vitamin A and fasting insulinemia (a), hs-CRP (b), or HDL cholesterol (c) plasma levels
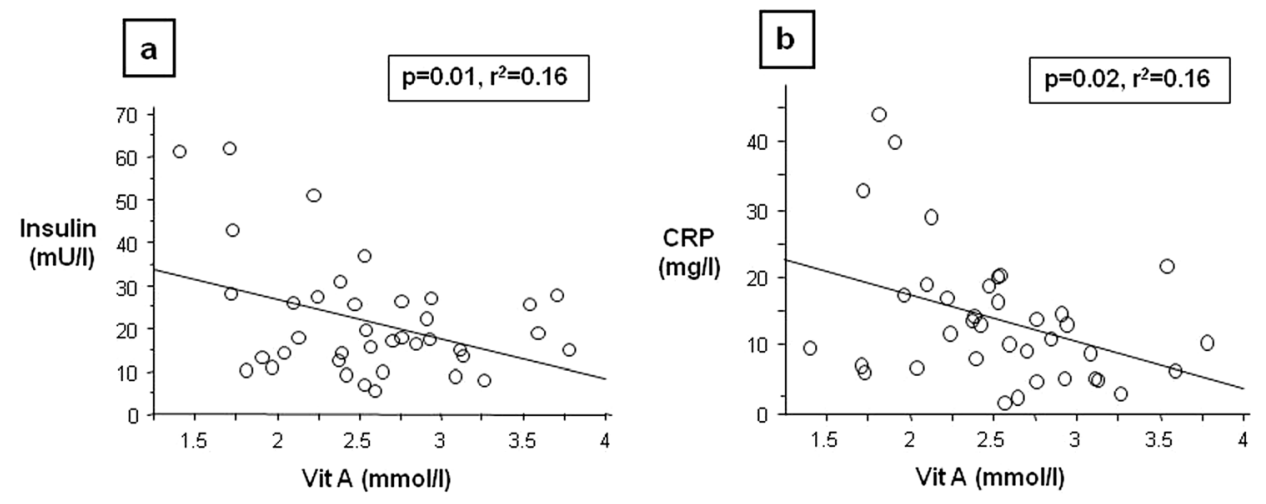
Table 2 Circulating plasma levels of fatty acids and vitamins $\mathrm{A}$ and $\mathrm{E}$, measured at baseline and 6 months after RYGB

\begin{tabular}{|c|c|c|c|}
\hline & Baseline & 6 months after RYGB & $p$ value \\
\hline \multicolumn{4}{|l|}{ Saturated fatty acids } \\
\hline Myristic $(\mu \mathrm{mol} / \mathrm{l})$ & $16.9 \pm 5.4(17.5 \pm 5.2)$ & $15.5 \pm 8.7$ & NS \\
\hline Pentadecanoic ( $\mu \mathrm{mol} / \mathrm{l})$ & $9.0 \pm 2.5(9.4 \pm 2.8)$ & $8.1 \pm 2.4$ & NS \\
\hline Palmitic $(\mu \mathrm{mol} / \mathrm{l})$ & $1181 \pm 294(1196 \pm 261.5)$ & $1047 \pm 199$ & 0.003 \\
\hline Stearic $(\mu \mathrm{mol} / \mathrm{l})$ & $591 \pm 125.1(611.4 \pm 118.9)$ & $432.7 \pm 80.7$ & $<0.0001$ \\
\hline \multicolumn{4}{|l|}{ Monounsaturated fatty acids } \\
\hline Palmitoleic $(\mu \mathrm{mol} / 1)$ & $30.1 \pm 12.6(30.3 \pm 11.9)$ & $21.7 \pm 8.1$ & 0.003 \\
\hline Cis-vaccenic $(\mu \mathrm{mol} / \mathrm{l})$ & $50.6 \pm 11.5(50.3 \pm 10.9)$ & $56.2 \pm 11$ & 0.01 \\
\hline Oleic $(\mu \mathrm{mol} / 1)$ & $385.5 \pm 94.4(395.7 \pm 91.1)$ & $362.6 \pm 66$ & NS \\
\hline Trans-vaccenic $(\mu \mathrm{mol} / \mathrm{l})$ & $8.1 \pm 2.5(8.3 \pm 2.6)$ & $6.4 \pm 2.6$ & 0.02 \\
\hline Trans-elaidic $(\mu \mathrm{mol} / \mathrm{l})$ & $2.5 \pm 1.2(2.5 \pm 1.1)$ & $2.2 \pm 0.8$ & NS \\
\hline \multicolumn{4}{|l|}{$\omega-6$ Polyunsaturated fatty acids } \\
\hline Linoleic $(\mu \mathrm{mol} / \mathrm{l})$ & $801.6 \pm 184.7(811 \pm 165.1)$ & $601.2 \pm 129.8$ & $<0.0001$ \\
\hline$\gamma$-Linolenic $(\mu \mathrm{mol} / \mathrm{l})$ & $5.0 \pm 2.3(5.3 \pm 2.3)$ & $2.5 \pm 1.2$ & $<0.0001$ \\
\hline Dihomo- $\gamma$-linolenic $(\mu \mathrm{mol} / \mathrm{l})$ & $166.1 \pm 52.9(175.7 \pm 52.6)$ & $98.1 \pm 30.4$ & $<0.0001$ \\
\hline Arachidonic $(\mu \mathrm{mol} / \mathrm{l})$ & $420.1 \pm 126.6(426.2 \pm 117.4)$ & $444.1 \pm 111.1$ & 0.03 \\
\hline \multicolumn{4}{|l|}{$\omega-3$ Polyunsaturated fatty acids } \\
\hline$\alpha$-Linolenic $(\mu \mathrm{mol} / \mathrm{l})$ & $8.2 \pm 3.4(8.3 \pm 3)$ & $4.7 \pm 1.9$ & $<0.0001$ \\
\hline Eicosapentaenoic $(\mu \mathrm{mol} / 1)$ & $36.6 \pm 20.3(36.2 \pm 18.9)$ & $21.1 \pm 11.6$ & $<0.0001$ \\
\hline Docosa-pentaenoic $(\mu \mathrm{mol} / \mathrm{l})$ & $38.0 \pm 15.4(37.2 \pm 13.8)$ & $31.8 \pm 8.9$ & 0.04 \\
\hline Docosahexaenoic $(\mu \mathrm{mol} / \mathrm{l})$ & $145.0 \pm 57.5(137.3 \pm 51.7)$ & $148.8 \pm 41.9$ & NS \\
\hline \multicolumn{4}{|l|}{ Vitamins } \\
\hline Vitamin A $(\mu \mathrm{mol} / \mathrm{l})$ & $2.6 \pm 0.6(2.5 \pm 0.5)$ & $2.0 \pm 0.61$ & $<0.0001$ \\
\hline Vitamin E $(\mu \mathrm{mol} / \mathrm{l})$ & $31.9 \pm 8.8(32.4 \pm 7.9)$ & $23.7 \pm 5.1$ & $<0.0001$ \\
\hline
\end{tabular}

particularly interesting. In fact, one should consider that $\omega-3$ FA are one of the multiple factors that may influence depression and mental health. Thus, their effect could be positively or negatively modulated by the presence of other environmental factors such as the more or less high degree of stress, the social class membership, or diet composition, beside $\omega-3$ FA intake. Another important point raised by Grosso et al. is that, in experimental studies, the efficacy of the $\omega-3$ FA supplementation could depend on the gravity of depression, a more noticeable effect being achieved in the presence of severe symptoms of depression.

In conclusion, if the role of $\omega-3 \mathrm{FA}$ seems promising, several aspects have to be clarified concerning the conditions at which they could be useful in the preventions and/or the treatment of depression. In this context, the results of our study bring an original contribution. In our knowledge, this is the first demonstration that circulating levels of several FA from both monounsaturated and polyunsaturated groups are significantly and negatively associated with the depression score in morbidly obese subjects.

It is well known that, due to their alimentary habits, obese subjects do not consume sufficient amounts of unsaturated FA. On the other hand, it has been repeatedly reported that the frequency of depression is significantly more elevated in obese populations, as compared to that in normal-weight subjects [26]. Our results, therefore, are of interest since they indicate that it could be possible to improve the psychological function of obese patients, by modifying their nutritional profile.

We also observed that some fatty acids show a negative association with several obesity-related parameters. In particular, the $\omega-3$ polyunsaturated eicosapentaenoic acid is negatively related to both circulating fasting insulin and hs-CRP and positively to HDL cholesterol. Several studies have evidenced the links between $\omega-3$ polyunsaturated FA with both metabolic syndrome and insulin resistance [27], typically present in obese subjects. Of note, both metabolic alterations [28] and depression [29] are associated with a low-degree inflammatory state, often evidenced by increased hs-CRP. It has been demonstrated that the beneficial effect of eicosapentaenoic acid on insulin resistance is, at least in part, mediated by its anti-inflammatory action [30]. A similar mechanism has been proposed to explain the positive effects of $\omega-3$ FA on depression [17]. It should be recalled that eicosapentaenoic acid enhances the absorption of vit A [31] which, in turn, exerts important anti-obesity [32] and antiinflammatory actions [33]. In our study, eicosapentaenoic acid and vit A showed a strong relationship and, in addition, were 
both significantly and negatively associated with fasting insulinemia and hs-CRP. Our results are, therefore, consistent with the experimental data of the literature and underline the involvement of eicosapentaenoic acid and vit $\mathrm{A}$ in metabolic and inflammatory functions, in obese humans.

It is well known that RYGB induces deep modifications in nutrient intake and absorption; therefore, we investigated the evolutive profile of circulating fatty acids and liposoluble vitamins A and E (Table 2). We observed that, before surgery, vit $\mathrm{A}$ is associated with several fatty acids, namely with eicosapentaenoic acid $(p<0.0001)$. A study, performed in animals, demonstrated that eicosapentaenoic acid increases the intestinal absorption of vit A [31], as already mentioned. Our results suggest that this particular affinity between eicosapentaenoic acid and vit A could exist also in humans. Vit A also showed relationship with all the saturated FA, but with a lower degree of significance. The latter relationship became stronger, after surgery, whereas the one with $\omega-3$ became weaker. It is known that each fat soluble vitamin has more marked affinity with different FA. Our results could indicate that the remarkable reduction of $\omega-3$ family FA
(Table 3) leads to an enhanced link of vit A with saturated FA.

A clinical study reported that vit A circulating levels lower than $2.4 \mu \mathrm{mol} / 1$ are significantly associated with increased risk of cardiovascular disease [34]. Before surgery, already $69 \%$ of our patients showed vit A circulating values behind $2.4 \mu \mathrm{mol} / \mathrm{l}$, and 6 months after the operation, the percentage rose to $79 \%$. This result underlines that it is of primary importance to detect micronutritional deficiencies before as well as after bariatric surgery. This is particularly relevant in the case of vit A which plays multiple roles in inflammation, insulin resistance, and anti-oxidative function. The significant relationship between vit $\mathrm{A}$ and fasting insulinemia, hsCRP, and HDL cholesterol, found in our study, supports this concept and also reinforces the idea that low levels of vit A could facilitate the occurrence of cardiovascular diseases.

The decrease in vit A circulating levels was significantly related with the RYGB-induced reduction of fat mass ( $p=$ $0.03)$. It has been demonstrated that adipose tissue is the site where vit A is stocked, elaborated, and released [35]. Our

Table 3 Relationship between fatty acids and vitamin A and E, respectively, at baseline and 6 months after RYGB

\begin{tabular}{|c|c|c|c|c|}
\hline & \multicolumn{2}{|c|}{ Vitamin A } & \multicolumn{2}{|c|}{ Vitamin E } \\
\hline & $\begin{array}{l}\text { Baseline } \\
p \text { value }\end{array}$ & $\begin{array}{l}6 \text { months after RYGB } \\
p \text { value }\end{array}$ & $\begin{array}{l}\text { Baseline } \\
p \text { value }\end{array}$ & $\begin{array}{l}6 \text { months after } \mathrm{RYGB} \\
p \text { value }\end{array}$ \\
\hline \multicolumn{5}{|l|}{ Saturated fatty acids } \\
\hline Myristic $(\mu \mathrm{mol} / \mathrm{l})$ & 0.02 & NS & NS & NS \\
\hline Pentadecanoic $(\mu \mathrm{mol} / \mathrm{l})$ & 0.03 & 0.001 & NS & NS \\
\hline Palmitic $(\mu \mathrm{mol} / \mathrm{l})$ & 0.04 & 0.03 & 0.0002 & 0.001 \\
\hline Stearic $(\mu \mathrm{mol} / \mathrm{l})$ & 0.03 & 0.009 & $<0.0001$ & 0.01 \\
\hline \multicolumn{5}{|l|}{ Monounsaturated fatty acids } \\
\hline Palmitoleic $(\mu \mathrm{mol} / \mathrm{l})$ & NS & NS & NS & NS \\
\hline Cis-vaccenic $(\mu \mathrm{mol} / \mathrm{l})$ & NS & NS & 0.01 & NS \\
\hline Oleic $(\mu \mathrm{mol} / \mathrm{l})$ & 0.02 & 0.03 & 0.0007 & 0.007 \\
\hline Trans-vaccenic $(\mu \mathrm{mol} / \mathrm{l})$ & 0.004 & NS & 0.002 & NS \\
\hline Trans-elaidic $(\mu \mathrm{mol} / \mathrm{l})$ & NS & NS & 0.01 & NS \\
\hline \multicolumn{5}{|l|}{$\omega-6$ Polyunsaturated fatty acids } \\
\hline Linoleic $(\mu \mathrm{mol} / \mathrm{l})$ & NS & NS & $<0.0001$ & 0.002 \\
\hline$\gamma$-Linolenic $(\mu \mathrm{mol} / \mathrm{l})$ & NS & NS & 0.03 & NS \\
\hline Dihomo- $\gamma$-linolenic $(\mu \mathrm{mol} / \mathrm{l})$ & NS & 0.003 & 0.001 & 0.003 \\
\hline Arachidonic $(\mu \mathrm{mol} / \mathrm{l})$ & 0.01 & NS & 0.0005 & 0.005 \\
\hline \multicolumn{5}{|l|}{$\omega-3$ Polyunsaturated fatty acids } \\
\hline$\alpha$-Linolenic $(\mu \mathrm{mol} / \mathrm{l})$ & NS & NS & 0.0001 & NS \\
\hline Eicosapentaenoic $(\mu \mathrm{mol} / \mathrm{l})$ & $<0.0001$ & 0.01 & 0.04 & NS \\
\hline Docosa-pentaenoic $(\mu \mathrm{mol} / \mathrm{l})$ & 0.003 & 0.02 & NS & NS \\
\hline Docosahexaenoic $(\mu \mathrm{mol} / \mathrm{l})$ & NS & 0.02 & NS & NS \\
\hline
\end{tabular}

Simple regression analysis 
result is therefore consistent with the role of adipose tissue in the regulation of vit A circulating levels.

Unexpectedly, we observed that preoperative circulating levels of linoleic acid are predictive of BMI reduction, 6 months after surgery (Fig. 3). This association persists after adjustment for age and initial BMI which are, in the literature, the only recognized predictive factors of bariatric surgery-induced weight loss [36]. This rather original result is in our opinion of potential interest. In fact, several studies conducted in animals have shown that linoleic acid facilitates the reduction of fat mass [37]. In another hand, in vitro studies demonstrated a stimulatory effect of this acid on oxidative activity of human skeletal muscle cells [38]. However, linoleic acid administration to humans submitted to hypocaloric diet did not lead to consistent results, in terms of reduction of fat mass [39]. A more recent study could be of interest to explain our results. In the attempt to modelize the direct delivering of nutrients in the jejunum occurring after gastric bypass; Dailey and coworkers infused intrajejunely linoleic acid, in rats [40]. This administration led to significant reduction of food intake and body weight, and these effects were mediated by a stimulation of glucagon-like peptide 1 (GLP-1) intestinal secretion. Authors conclude that the increased secretion of GLP-1, stimulated by the arrival of undigested nutrient in the jejunum, could be one of the mechanisms through which gastric bypass yields greater weight reduction as well as diabetes remission, as compared to other restrictive bariatric techniques [40]. Thus, a higher linoleic acid consumption could lead to a larger weight reduction also in humans, and this could explain our observation.

In conclusion, we have evidenced potential implications of FA in several biological and psychological functions. Because of its restrictive and malabsorptive effects, RYGB induces a remarkable reduction of the circulating levels of these substances which could have deleterious consequences not only on vitamin absorption but also on metabolism, cardiovascular function, and depression. Thus, the detection of FA deficiencies is of primary importance both before and after bariatric surgery, in order to optimize the effects of the intervention as well as to prevent the occurrence of metabolic and/or cardiovascular complications.

\section{Conflict of Interest All authors declare no conflict of interest.}

Statement of Informed Consent Informed consent was obtained from all individual participants included in the study.

Statement of Human and Animal Rights All procedures performed in this study were in accordance with the ethical standards of the institutional and/or national research committee and with the 1964 Helsinki Declaration and its later amendments or comparable ethical standards.

\section{References}

1. Sturm R, Hattori A. Morbid obesity rates continue to rise rapidly in the United States. Int J Obes (Lond). 2013;37:889-91.

2. Lohrmann D, YoussefAgha A, Jayawardene W. Trends in body mass index and prevalence of extreme high obesity among Pennsylvania children and adolescents, 2007-2011: promising but cautionary. Am J Public Health. 2014;104:e62-8.

3. Hubert HB, Feinleib M, McNamara PM, et al. Obesity as an independent risk factor for cardiovascular disease: a 26-year follow-up of participants in the Framingham Heart Study. Circulation. 1983;67: 968-77.

4. Jagielski AC, Brown A, Hosseini-Araghi M, et al. The association between adiposity, mental well-being, and quality of life in extreme obesity. PLoS One. 2014;9:e92859.

5. Sjostrom L. Review of the key results from the Swedish Obese Subjects (SOS) trial - a prospective controlled intervention study of bariatric surgery. J Intern Med. 2013;273:219-34.

6. Aftab H, Risstad H, Sovik TT, et al. Five-year outcome after gastric bypass for morbid obesity in a Norwegian cohort. Surg Obes Relat Dis. 2014;10:71-8

7. Madan AK, Orth WS, Tichansky DS, et al. Vitamin and trace mineral levels after laparoscopic gastric bypass. Obes Surg. 2006;16:603-6.

8. Bal BS, Finelli FC, Shope TR, et al. Nutritional deficiencies after bariatric surgery. Nat Rev Endocrinol. 2012;8:544-56.

9. Lorente-Cebrian S, Costa AG, Navas-Carretero S, et al. Role of omega-3 fatty acids in obesity, metabolic syndrome, and cardiovascular diseases: a review of the evidence. J Physiol Biochem. 2013;69: 633-51.

10. Rizos EC, Ntzani EE, Bika E, et al. Association between omega-3 fatty acid supplementation and risk of major cardiovascular disease events: a systematic review and meta-analysis. JAMA. 2012;308: 1024-33.

11. Ernst B, Thurnheer M, Schmid SM, et al. Evidence for the necessity to systematically assess micronutrient status prior to bariatric surgery. Obes Surg. 2009; 19:66-73.

12. Damms-Machado A, Weser G, Bischoff SC. Micronutrient deficiency in obese subjects undergoing low calorie diet. Nutr J. 2012;11:34.

13. Kimmons JE, Blanck HM, Tohill BC, et al. Associations between body mass index and the prevalence of low micronutrient levels among US adults. MedGenMed. 2006;8:59.

14. Correia Horvath JD, Dias de Castro ML, Kops N, et al. Obesity coexists with malnutrition? Adequacy of food consumption by severely obese patients to dietary reference intake recommendations. Nutr Hosp. 2014;29:292-9.

15. Ju SY, Lee YJ, Jeong SN. Serum 25-hydroxyvitamin D levels and the risk of depression: a systematic review and meta-analysis. J Nutr Health Aging. 2013;17:447-55.

16. Murakami K, Miyake Y, Sasaki S, et al. Fish and n-3 polyunsaturated fatty acid intake and depressive symptoms: Ryukyus Child Health Study. Pediatrics. 2010;126:e623-30.

17. Grosso G, Pajak A, Marventano S, et al. Role of omega-3 fatty acids in the treatment of depressive disorders: a comprehensive metaanalysis of randomized clinical trials. PLoS One. 2014;9:e96905.

18. Zigmond AS, Snaith RP. The hospital anxiety and depression scale. Acta Psychiatr Scand. 1983;67:361-70.

19. Kolotkin RL, Crosby RD, Williams GR. Health-related quality of life varies among obese subgroups. Obes Res. 2002;10:74856.

20. Chajes V, Hulten K, Van Kappel AL, et al. Fatty-acid composition in serum phospholipids and risk of breast cancer: an incident casecontrol study in Sweden. Int J Cancer. 1999;83:585-90.

21. Gueguen S, Herbeth B, Siest G, et al. An isocratic liquid chromatographic method with diode-array detection for the simultaneous determination of alpha-tocopherol, retinol, and 
five carotenoids in human serum. J Chromatogr Sci. 2002;40: 69-76.

22. Tanskanen A, Hibbeln JR, Tuomilehto J, et al. Fish consumption and depressive symptoms in the general population in Finland. Psychiatr Serv. 2001;52:529-31.

23. Astorg P, Couthouis A, Bertrais S, et al. Association of fish and long-chain n-3 polyunsaturated fatty acid intakes with the occurrence of depressive episodes in middle-aged French men and women. Prostaglandins Leukot Essent Fat Acids. 2008;78: 171-82.

24. Lucas M, Mirzaei F, O'Reilly EJ, et al. Dietary intake of n-3 and n-6 fatty acids and the risk of clinical depression in women: a 10-y prospective follow-up study. Am J Clin Nutr. 2011;93:1337-43.

25. Rogers PJ, Appleton KM, Kessler D, et al. No effect of n-3 longchain polyunsaturated fatty acid (EPA and DHA) supplementation on depressed mood and cognitive function: a randomised controlled trial. Br J Nutr. 2008;99:421-31.

26. Zhao G, Ford ES, Dhingra S, et al. Depression and anxiety among US adults: associations with body mass index. Int J Obes (Lond). 2009;33:257-66.

27. Robinson LE, Buchholz AC, Mazurak VC. Inflammation, obesity, and fatty acid metabolism: influence of n-3 polyunsaturated fatty acids on factors contributing to metabolic syndrome. Appl Physiol Nutr Metab. 2007;32:1008-24.

28. Devaraj S, Singh U, Jialal I. Human C-reactive protein and the metabolic syndrome. Curr Opin Lipidol. 2009;20:182-9.

29. Liukkonen T, Silvennoinen-Kassinen S, Jokelainen J, et al. The association between C-reactive protein levels and depression: results from the northern Finland 1966 birth cohort study. Biol Psychiatry. 2006;60:825-30.

30. Kalupahana NS, Claycombe K, Newman SJ, et al. Eicosapentaenoic acid prevents and reverses insulin resistance in high-fat diet-induced obese mice via modulation of adipose tissue inflammation. J Nutr. 2010;140:1915-22.
31. Raju M, Lakshminarayana R, Krishnakantha TP, et al. Micellar oleic and eicosapentaenoic acid but not linoleic acid influences the betacarotene uptake and its cleavage into retinol in rats. Mol Cell Biochem. 2006;288:7-15.

32. Mercader J, Ribot J, Murano I, et al. Remodeling of white adipose tissue after retinoic acid administration in mice. Endocrinology. 2006;147:5325-32.

33. Landrier JF, Marcotorchino J, Tourniaire F. Lipophilic micronutrients and adipose tissue biology. Nutrients. 2012;4:1622-49.

34. Gey KF, Ducimetiere P, Evans A, et al. Low plasma retinol predicts coronary events in healthy middle-aged men: the PRIME Study. Atherosclerosis. 2010;208:270-4.

35. Frey SK, Vogel S. Vitamin A metabolism and adipose tissue biology. Nutrients. 2011;3:27-39.

36. Bobbioni-Harsch E, Huber O, Morel P, et al. Factors influencing energy intake and body weight loss after gastric bypass. Eur J Clin Nutr. 2002;56:551-6.

37. Koba K, Akahoshi A, Yamasaki M, et al. Dietary conjugated linolenic acid in relation to CLA differently modifies body fat mass and serum and liver lipid levels in rats. Lipids. 2002;37: 343-50.

38. Vaughan RA, Garcia-Smith R, Bisoffi M, et al. Conjugated linoleic acid or omega 3 fatty acids increase mitochondrial biosynthesis and metabolism in skeletal muscle cells. Lipids Health Dis. 2012;11:142.

39. Onakpoya IJ, Posadzki PP, Watson LK, et al. The efficacy of longterm conjugated linoleic acid (CLA) supplementation on body composition in overweight and obese individuals: a systematic review and meta-analysis of randomized clinical trials. Eur J Nutr. 2012;51: 127-34.

40. Dailey MJ, Moghadam AA, Moran TH. Jejunal linoleic acid infusions require GLP-1 receptor signaling to inhibit food intake: implications for the effectiveness of Roux-en-Y gastric bypass. Am J Physiol Endocrinol Metab. 2011;301:E1184-90. 